\title{
TEOREMA PYTHAGORAS PADA BIDANG TAXICAB
}

\author{
ZULVIATI PUTRI \\ Program Studi Matematika, \\ Fakultas Matematika dan Ilmu Pengetahuan Alam, Universitas Andalas Padang, \\ Kampus UNAND Limau Manis Padang, Indonesia \\ zulviatiputri@gmail.com
}

\begin{abstract}
Abstrak. Geometri Taxicab adalah bentuk geometri dimana fungsi jarak atau metrik dari geometri Euclidean diganti dengan metrik baru dimana jarak antara dua titik adalah jumlah dari perbedaan mutlak dari koordinat-koordinatnya, atau dapat ditulis :

$$
d_{T}\left(\left(x_{1}, y_{1}\right),\left(x_{2}, y_{2}\right)\right)=\left|x_{1}-x_{2}\right|+\left|y_{1}-y_{2}\right|
$$

Tulisan ini bertujuan untuk mengkaji kembali tentang teorema Pythagoras pada bidang Taxicab. Teorema Pythagoras yang diperoleh pada bidang Taxicab bergantung kepada posisi segitiga siku-siku pada bidang koordinat serta menggunakan kemiringan dan jarak pada bidang Taxicab.

Kata Kunci: Jarak bidang Taxicab, Teorema Pythagoras, dan Kemiringan,
\end{abstract}

\section{Pendahuluan}

Dalam [2] Minkowski menemukan sebuah geometri yaitu geometri Taxicab $d_{T}\left(\left(x_{1}, y_{1}\right),\left(x_{2}, y_{2}\right)\right)=$ $\left|x_{1}-x_{2}\right|+\left|y_{1}-y_{2}\right|[1]$. Geometri Taxicab adalah bentuk geometri dimana fungsi jarak atau metrik dari geometri Euclidean diganti dengan metrik baru dimana jarak antara dua titik adalah jumlah nilai mutlak dari selisih absis dan selisih ordinat pada koordinat kartesius. Dalam [3] Krause telah mengembangkan tentang geometri Taxicab. Dalam paper ini akan dikaji kembali tentang teorema Pythagoras pada geometri Taxicab.

\section{Teorema Pythagoras pada Bidang Taxicab}

Telah dikenal bahwa jika $\mathrm{ABC}$ adalah segitiga dengan sudut siku-siku di A dalam bidang Euclidean, maka $a^{2}=b^{2}+c^{2}$ dimana $a=d_{E}(B, C), b=d_{E}(A, C)$ dan $c=$ $d_{E}(A, B)$ ini adalah teorema Pythagoras. Persamaan berikut memperlihatkan hubungan antara jarak Euclidean dengan jarak Taxicab antara dua titik pada bidang koordinat kartesius.

Lema 1. [2] Misal titik $A$ dan $B$ tidak berada pada satu garis vertikal, yaitu $A\left(x_{1}, y_{1}\right)$ dan $B\left(x_{2}, y_{2}\right)$ dimana $x_{1} \neq x_{2}$. Jika $m$ adalah kemiringan garis melalui titik $A$ dan $B$, maka

$$
d_{E}(A, B)=\frac{\left(1+m^{2}\right)}{(1+|m|)} d_{T}(A, B)
$$

Jika $A$ dan $B$ berada pada satu garis vertikal, maka $d_{E}(A, B)=d_{T}(A, B)$. 
Bukti. Misal $A\left(x_{1}, y_{1}\right)$ dan $B\left(x_{2}, y_{2}\right)$ dengan $x_{1} \neq x_{2}$ maka $m=\frac{\left(y_{2}-y_{1}\right)}{\left(x_{2}-x_{1}\right)}$. Persamaan (1) diperoleh dengan perhitungan dari kemiringan $(m)$, definisi jarak Euclid dan Taxicab.

Fakta lain yang berguna yang dapat dibuktikan dengan perhitungan langsung adalah sebagai berikut:

Lema 2. [2] Dua garis $l_{1}$ dan $l_{2}$ mempunyai kemiringan berturut-turut $m_{1}$ dan $m_{2}$, jika $m_{1} \neq 0$ dan $m_{2}=\frac{-1}{m_{1}}$, maka berlaku

$$
\frac{\sqrt{1+m_{1}^{2}}}{1+\left|m_{1}\right|}=\frac{\sqrt{1+m_{2}^{2}}}{1+\left|m_{2}\right|}
$$

Lema berikut menyatakan bahwa rasio jarak Taxicab dan jarak Euclidean adalah sama, walaupun kedua jarak mempunyai definisi yang berbeda.

Lema 3. [2] Misalkan segitiga ABC adalah segitiga siku-siku di $A$, jika b dan $c$ adalah panjang sisi kaki-kaki pada segitiga $A B C$ di Euclidean, sedangkan $b_{T}$ dan $c_{T}$ adalah panjang sisi kaki-kaki pada segitiga $A B C$ di Taxicab, maka

$$
\frac{b}{c}=\frac{b_{T}}{c_{T}} .
$$

Bukti. Jika panjang kaki AB dan AC pada segitiga ABC adalah sejajar dengan sumbu koordinat, maka $b=b_{T}$ dan $c=c_{T}$ dan dua rasio ini adalah sama. Jika salah satu kaki dari segitiga ABC tidak sejajar dengan sumbu koordinat, dimana kemiringan $\mathrm{AB}$ adalah $m_{1}$, maka kemiringan $\mathrm{AC}$ adalah $m_{2}=\frac{-1}{m_{1}}$, karena kakikaki segitiga ABC tegak lurus. Dari persamaan (1) maka, $c=\frac{\sqrt{1+m_{1}^{2}}}{1+\left|m_{1}\right|} c_{T}$ dan $b=\frac{\sqrt{1+m_{2}^{2}}}{1+\left|m_{2}\right|} b_{T}$, tetapi dengan menggunakan persamaan (2) didapat $\frac{b}{c}=\frac{b_{T}}{c_{T}}$.

Teorema 1. [1] Misalkan $a_{T}$ adalah panjang sisi miring, $b_{T}$ dan $c_{T}$ adalah panjang kaki-kaki dari segitiga $A B C$ dengan sudut siku-siku pada $A$ di bidang Taxicab, maka

1. Jika kedua sisi siku-siku masing-masing sejajar dengan garis dasar yang bersesuaian, maka

$$
a_{T}=b_{T}+c_{T}
$$

2. jika tidak ada sisi siku-siku yang sejajar dengan garis dasar dimana $\curlyvee=$ $d_{T}(A, H)$ dan $H=$ titik proyeksi ortogonal dari $B$ atau $C$ untuk garis dasar melalui A, maka

$$
a_{T}=b_{T}+c_{T}-2_{\curlyvee}
$$

Bukti. Misalkan A adalah titik siku-siku pada segitiga ABC. Berikut kita lihat dua kasus dibawah ini :

Kasus 1. Jika kedua sisi siku-siku masing-masing sejajar dengan garis dasar yang bersesuaian, maka garis dasar bertepatan dengan sisi tegak lurus dari ABC seperti pada gambar 2.1. Misal koordinat titik-titik $B=\left(x_{1}, y_{1}\right), C=\left(x_{2}, y_{2}\right)$ dan $A=\left(x_{2}, y_{1}\right)$, dengan menggunakan definisi jarak Taxicab maka didapat,

$$
\begin{gathered}
b_{T}=\left|x_{2}-x_{2}\right|+\left|y_{2}-y_{1}\right|=\left|y_{2}-y_{1}\right| c_{T}=\left|x_{2}-x_{1}\right|+\left|y_{1}-y_{1}\right|=\left|x_{2}-x_{1}\right| \\
a_{T}=\left|x_{2}-x_{1}\right|+\left|y_{2}-y_{1}\right|=c_{T}+b_{T}
\end{gathered}
$$


Jadi, jelas $a_{T}=b_{T}+c_{T}$.

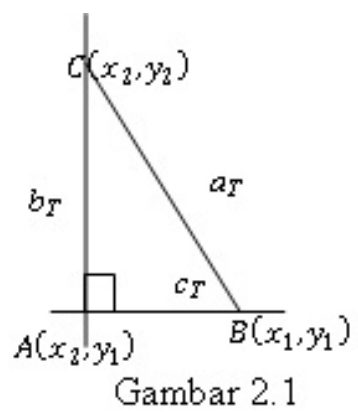

Kasus 2. Misal $b_{1}, b_{2}, c_{1}$ dan $c_{2}$ adalah parameter seperti pada gambar 2.2, jika tidak ada sisi siku-siku yang sejajar dengan garis dasar seperti pada Gambar 2.2 , dan

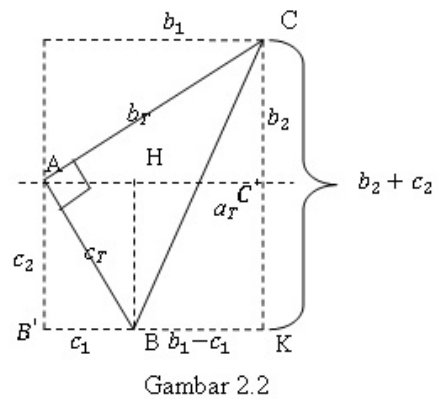

$b_{T}=d\left(A, C^{\prime}\right)+d\left(C, C^{\prime}\right)=b_{1}+b_{2} c_{T}=d\left(A, B^{\prime}\right)+d\left(B, B^{\prime}\right)=c_{2}+c_{1}$, maka $a_{T}=$ $b_{1}-c_{1}+b_{2}+c_{2}$ dimana $c_{1}=d_{T}\left(B, B^{\prime}\right)=d_{T}(A, H)=: \curlyvee a_{T}=b_{1}+b_{2}+c_{2}+c_{1}-2 c_{1}$ $a_{T}=b_{T}+c_{T}-2 c_{1}=b_{T}+c_{T}-2 \curlyvee$.

Pada teorema diatas telah diberikan teorema Pythagoras pada bidang Taxicab menggunakan parameter $\curlyvee$ yang merupakan panjang suatu bagian dari garis dasar. Dalam teorema berikut akan diberikan bentuk lain teorema Pythagoras pada bidang Taxicab dengan menggunakan kemiringan dan sisi dari segitiga siku-siku.

Teorema 2. [1] Misalkan $a_{T}$ panjang sisi miring, $b_{T}$ dan $c_{T}$ menyatakan panjang kaki segitiga siku-siku pada bidang Taxicab. Jika kemiringan sisi miring adalah $m_{1}$ dan kemiringan dari salah satu kaki segitiga adalah $m_{2}$, maka

$$
a_{T}^{2}=\rho\left(m_{1}, m_{2}\right) \cdot\left(b_{T}^{2}+c_{T}^{2}\right),
$$

dimana

$$
\rho\left(m_{1}, m_{2}\right)= \begin{cases}\left(\frac{1+m_{2}^{2}}{1+m_{1}^{2}}\right)\left(\frac{1+\left|m_{1}\right|}{1+\left|m_{2}\right|}\right)^{2} & , m_{1}, m_{2} \in \mathbb{R} \\ \left(\frac{\left(1+\left|m_{1}\right|\right)^{2}}{1+m_{1}^{2}}\right) & , m_{2} \rightarrow \infty \\ \left(\frac{1+m_{2}^{2}}{\left(1+\left|m_{2}\right|\right)^{2}}\right) & , m_{1} \rightarrow \infty .\end{cases}
$$

Bukti. Misal a adalah panjang sisi miring dan b, c adalah panjang sisi-sisi kaki di bidang Euclidean. Kemudian $m_{1}$ menunjukkan kemiringan sisi miring, dan $m_{2}, m_{3}$ menunjukkan kemiringan dari kaki-kaki segitiga. Berikut dilihat 3 kasus: 
1. jika $m_{2} \neq 0$ maka kemiringan dari kaki segitiga yang bersesuaiam $m_{3}$ adalah $\frac{-1}{m_{2}}$. Dengan demikian berdasar (1), diperoleh

$a=\frac{\left[\left(1+m_{1}^{2}\right)^{\left(\frac{1}{2}\right)}\right.}{\left.\left(\left(1+\left|m_{1}\right|\right)\right)\right]} \cdot a_{T}$

$b=\frac{\left[\left(1+m_{2}^{2}\right)^{\left(\frac{1}{2}\right)}\right.}{\left.\left(\left(1+\left|m_{2}\right|\right)\right)\right]} \cdot b_{T}$

$c=\left[\left(1+m_{2}^{2}\right)^{\left(\frac{1}{2}\right)}\left(\left(1+\left|m_{2}\right|\right)\right)\right] \cdot c_{T}$

2. Jika $m_{2}=0$, maka kemiringan $m_{3}$ adalah $\left.\frac{-1}{m_{2}}\right) \rightarrow \infty$ atau jika $m_{2} \rightarrow \infty$, maka kemiringan $m_{3}$ adalah $\frac{-1}{m_{2}} \rightarrow 0$, kemudian berlaku

$a=\frac{\left[\left(1+m_{1}^{2}\right)^{\frac{1}{2}}\right.}{\left(\left(1+\left|m_{1}\right|\right]\right.} \cdot a_{T}$
$b=b_{T}$
$c=c_{T}$

3. Jika $m_{1} \rightarrow \infty$, maka

$a=a_{T}$

$b=\frac{\left[\left(1+m_{2}^{2}\right)^{\frac{1}{2}}\right.}{\left.\left(\left(1+\left|m_{2}\right|\right)\right)\right]} \cdot b_{T}$

$c=\frac{\left[\left(1+m_{2}^{2}\right)^{\frac{1}{2}}\right.}{\left.\left(\left(1+\left|m_{2}\right|\right)\right)\right]} \cdot c_{T}$

Dengan mensubstitusikan nilai-nilai a,b, dan c dari masing-masing kasus 1), 2) dan 3) diatas kedalam teorema Pythagoras Euclidean, maka diperoleh hubungan berikut:

$$
a_{T}^{2}=\rho\left(m_{1}, m_{2}\right) \cdot\left(b_{T}^{2}+c_{T}^{2}\right)
$$

dimana

$$
\rho\left(m_{1}, m_{2}\right)= \begin{cases}\left(\frac{1+m_{2}^{2}}{1+m_{1}^{2}}\right)\left(\frac{1+\left|m_{1}\right|}{1+\left|m_{2}\right|}\right)^{2} & , m_{1}, m_{2} \in \mathbb{R} \\ \left(\frac{\left(1+\left|m_{1}\right|\right)^{2}}{1+m_{1}^{2}}\right) & , m_{2} \rightarrow \infty \\ \left(\frac{1+m_{2}^{2}}{\left(1+\left|m_{2}\right|\right)^{2}}\right) & , m_{1} \rightarrow \infty .\end{cases}
$$

Teorema 3. [2]

1. Jika kaki $A B C$ adalah sejajar dengan sumbu koordinat, maka

$$
a_{T}=b_{T}+c_{T}
$$

2. Jika kaki dari segitiga ABC tidak sejajar dengan sumbu koordinat, sisi miring $B C$ tidak vertikal terhadap sumbu koordinat, dan $m$ adalah kemiringan salah satu kaki, maka

$$
(1+|m|) a_{T}=\left|b_{T} m+c_{T}\right|+\left|c_{T} m-b_{T}\right| .
$$

Bukti. 1. Dengan menggunakan definisi jarak Taxicab, yang mana telah dikaji pada teorema 2.1, maka persamaan (7) terbukti.

2. Misal sudut CBA adalah $\theta$, perhatikan bahwa $\theta$ positif dan lancip (lihat gambar 2.3). Maka $\tan \theta=\frac{b}{c}=\frac{b_{T}}{c_{T}}$ berdasarkan Lema 2.3 .

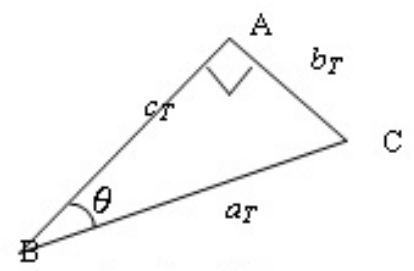

Gambar 2.3 
Misalkan m adalah kemiringan sisi $\mathrm{AB}, m_{3}=\frac{-1}{m}$ adalah kemiringan sisi $\mathrm{AC}$ dan $m_{1}$ adalah kemiringan sisi $\mathrm{BC}$, diketahui $\tan \theta=\frac{\left(m-m_{1}\right)}{\left(1+m m_{1}\right)}$, maka

$$
\frac{b_{T}}{c_{T}}=\frac{\left(m-m_{1}\right)}{\left(1+m m_{1}\right)} .
$$

Dari persamaan (9) akan dicari $m_{1}$, yaitu

$$
m_{1}=\frac{\left(c_{T} m-b_{T}\right)}{\left(b_{T} m+c_{T}\right)}, m \neq \frac{-c_{T}}{b_{T}} .
$$

Dengan menerapkan persamaan (1) ke teorema Pythagoras $a^{2}=b^{2}+c^{2}$ dan dengan menggunakan Lema 2.2, didapat

$$
\left(\frac{\sqrt{1+m_{1}^{2}}}{1+\left|m_{1}\right|^{2}}\right) a_{T}^{2}=\left(\frac{\sqrt{\left(1+m^{2}\right)}}{\left.(1+|m|)^{2}\right)}\left(b_{T}^{2}+c_{T}^{2}\right),\right.
$$

yang disederhanakan menjadi

$$
(1+|m|)^{2} a_{T}^{2}=\frac{\left(\left(1+\left|m_{1}\right|\right)^{2}\right.}{\left.\left(1+m_{1}^{2}\right)\right)\left(1+m^{2}\right)}\left(b_{T}^{2}+c_{T}^{2}\right) .
$$

Substitutusi $m_{1}$ yang terdapat dalam persamaan (10) ke persamaan (12) maka diperoleh, $(1+|m|) a_{T}=\left|b_{T} m+c_{T}\right|+\left|c_{T} m-b_{T}\right|$.

Akibat 1. [2] Jika BC sisi miring dari segitiga $A B C$ yang sejajar dengan sumbu koordinat, maka

$$
a_{T}=\frac{\left(\left(b_{T}^{2}+c_{T}^{2}\right)\right)}{\left(\left(b_{T}+c_{T}\right)\right)} .
$$

Jika $b_{T}=c_{T}$, maka $a_{T}=b_{T}=c_{T}$

Bukti. Jika BC sejajar dengan sumbu $x$, maka $m_{1}=0$, dan jika $\mathrm{BC}$ sejajar dengan sumbu $y$ maka $m_{1} \rightarrow \infty$. Dari kedua kasus tersebut didapat $\frac{\sqrt{\left(1+m_{1}^{2}\right)}}{\left(\left(1+\left|m_{1}\right|\right)\right.}=$ 1, maka persamaan (11) menjadi $a_{T}^{2}=\frac{\left(\sqrt{\left(1+m^{2}\right)}\right.}{(1+|m|))^{2}}\left(b_{T}^{2}+c_{T}^{2}\right)$, dimana $\mathrm{m}$ adalah kemiringan sisi AB. Misal AD adalah ketinggian dari A (lihat gambar 2.4). Dengan segitiga serupa dan lema 2.3, maka:
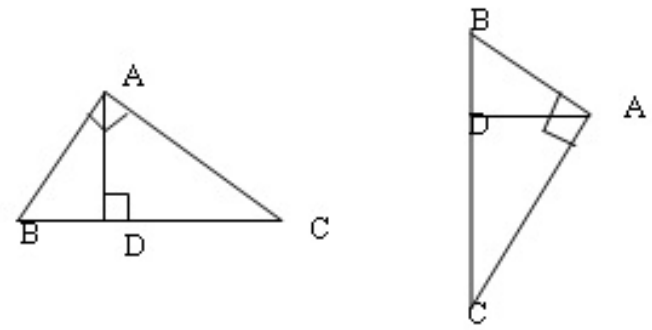

\section{Gambar 2.4}

1. jika BC horizontal dimana $|m|=\left|\frac{A D}{B D}\right|=\left|\frac{A C}{A B}\right|=\frac{b_{T}}{c_{T}}$,maka

$$
a_{T}^{2}=\left(\frac{\sqrt{\left(1+\frac{\left(b_{T}{ }^{2}\right.}{\left.c_{T}\right)}\right)}}{\left(1+\frac{\left(b_{T}\right.}{\left.\left.c_{T}\right)\right)^{2}}\right.}\left(b_{T}^{2}+c_{T}^{2}\right)\right. \text {. }
$$


2. jika BC vertikal dimana $|m|=\left|\frac{B D}{A D}\right|=\left|\frac{A B}{A C}\right|=c_{T} / b_{T}$, maka

$$
a_{T}^{2}=\left(\frac{\sqrt{\left(1+\frac{\left(c_{T}{ }^{2}\right.}{\left.b_{T}\right)}\right)}}{\left(1+\frac{\left(c_{T}\right.}{\left.\left.b_{T}\right)\right)^{2}}\right.}\left(b_{T}^{2}+c_{T}^{2}\right)\right. \text {. }
$$

Persamaan (14) dan (15) dapat disederhanakan menjadi $a_{T}^{2}=\frac{\left(b_{T}^{2}+c_{T}^{2}\right)^{2}}{\left(b_{T}+c_{T}\right)^{2}}$, yang setara dengan persamaan (13). Jika $b_{T}=c_{T}$, maka persamaan (13) tereduksi menjadi $a_{T}=b_{T}$. Tapi, $a_{T}=b_{T}=c_{T}$ dalam hal ini jelas bahwa segitiga $\mathrm{ABC}$ adalah segitiga siku-siku sama kaki.

Akibat 2. [2] Jika tidak ada sisi ABC sejajar dengan sumbu koordinat, dan $m_{1}$ adalah kemiringan sisi $B C$ yang merupakan sisi miring $A B C$, maka

$$
\frac{a_{T}}{\left(\left(1+\left|m_{1}\right|\right)\right)}=\frac{\left(\left(b_{T}^{2}+c_{T}^{2}\right)\right)}{\left(\left(\left|b_{T} m_{1}-c_{T}\right|+\left|c_{T} m_{1}+b_{T}\right|\right)\right)} .
$$

Bukti. Jika $m$ adalah kemiringan AB, maka dengan memecahkan persamaan (9) untuk $m$ :

$$
m=\frac{\left(\left(b_{T}+c_{T} m_{1}\right)\right)}{\left(\left(c_{T}-b_{T} m_{1}\right)\right)}
$$

Substitusi m ke persamaan (8) dan dan persamaan (16) terbukti

$$
\frac{a_{T}}{\left(\left(1+\left|m_{1}\right|\right)\right)}=\frac{\left(\left(b_{T}^{2}+c_{T}^{2}\right)\right)}{\left(\left(\left|b_{T} m_{1}-c_{T}\right|+\left|c_{T} m_{1}+b_{T}\right|\right)\right)} \text {. }
$$

\section{Kesimpulan}

Beberapa rumus yang dapat ditemukan dari geometri, salah satunya adalah teorema Pythagoras. Dari pembahasan di atas teorema Pythagoras yang diperoleh pada bidang Taxicab bergantung kepada posisi segitiga siku-siku pada bidang koordinat serta menggunakan kemiringan dan jarak pada bidang Taxicab.

\section{Ucapan Terima kasih}

Penulis mengucapkan terima kasih kepada para penguji Bapak Budi Rudianto, Bapak Zulakmal, dan Bapak Narwen yang telah memberikan masukan dan saran sehingga paper ini dapat diselesaikan dengan baik.

\section{Daftar Pustaka}

1. Kaya, Rustam. Colakglu, Harun Baris. 2006, Taxicab Versions of some Euclidean Theorems, Vol.26, No.1, pp 69-81. International Electronic Journal of Pure and Applied Mathematics.

2. Kaya, Rustam. Colakglu, Harun Baris. 2008. Taxicab Versions of The Pythagorean Theorem, The Pi Mu Epsilon Journal.Vol.12, No.9, pp 535-539.

3. Krause, Eugene F. 1986. Taxicab Geometry An Adventure in Non-Euclidean Geometry. Dover Publications, Inc., New York. 